\title{
Head impact exposure measured in a single youth football team during practice drills
}

\author{
Mireille E. Kelley, MS, ${ }^{1,2}$ Joeline M. Kane, BS, ${ }^{2}$ Mark A. Espeland, PhD, ${ }^{3}$ Logan E. Miller, MS, ${ }^{1,2}$ \\ Alexander K. Powers, MD, ${ }^{4}$ Joel D. Stitzel, PhD, ${ }^{1,2}$ and Jillian E. Urban, $\mathrm{PhD}^{1,2}$ \\ 'Virginia Tech-Wake Forest University School of Biomedical Engineering and Sciences; and Departments of ${ }^{2}$ Biomedical \\ Engineering, ${ }^{3}$ Biostatistical Sciences, and ${ }^{4}$ Neurosurgery, Wake Forest School of Medicine, Winston-Salem, North Carolina
}

OBJECTIVE This study evaluated the frequency, magnitude, and location of head impacts in practice drills within a youth football team to determine how head impact exposure varies among different types of drills.

METHODS On-field head impact data were collected from athletes participating in a youth football team for a single season. Each athlete wore a helmet instrumented with a Head Impact Telemetry (HIT) System head acceleration measurement device during all preseason, regular season, and playoff practices. Video was recorded for all practices, and video analysis was performed to verify head impacts and assign each head impact to a specific drill. Eleven drills were identified: dummy/sled tackling, install, special teams, Oklahoma, one-on-one, open-field tackling, passing, position skill work, multiplayer tackle, scrimmage, and tackling drill stations. Generalized linear models were fitted to log-transformed data, and Wald tests were used to assess differences in head accelerations and impact rates.

RESULTS A total of 2125 impacts were measured during 30 contact practices in 9 athletes (mean age $11.1 \pm 0.6$ years, mean mass $44.9 \pm 4.1 \mathrm{~kg})$. Open-field tackling had the highest median and 95th percentile linear accelerations $(24.7 \mathrm{~g}$ and $97.8 \mathrm{~g}$, respectively) and resulted in significantly higher mean head accelerations than several other drills. The multiplayer tackle drill resulted in the highest head impact frequency, with an average of 0.59 impacts per minute per athlete, but the lowest 95th percentile linear accelerations of all drills. The front of the head was the most common impact location for all drills except dummy/sled tackling.

CONCLUSIONS Head impact exposure varies significantly in youth football practice drills, with several drills exposing athletes to high-magnitude and/or high-frequency head impacts. These data suggest that further study of practice drills is an important step in developing evidence-based recommendations for modifying or eliminating certain high-intensity drills to reduce head impact exposure and injury risk for all levels of play.

https://thejns.org/doi/abs/10.3171/2017.5.PEDS16627

KEY WORDS pediatrics; football; head impacts; biomechanics; acceleration; concussion; trauma

1 PPROXIMATELY 5 million athletes play organized football in the United States-2000 National Football League (NFL), 100,000 college, 1.3 million high school, and 3.5 million youth players..$^{11,16,30}$ Even though youth athletes make up the largest proportion of football participants, youth football has seen declines in participation in recent years. ${ }^{36,37}$ Several factors may be contributing to the decline in participation; concern over injuries, the high prevalence of concussions, and the longterm effects of repetitive head impacts in particular have been suggested as major reasons., ${ }^{1,6,15,24}$ Increased public awareness and improved concussion management have contributed to increases in the number of concussions evaluated by clinicians; ${ }^{40}$ however, the relationship between youth sports participation and long-term neurological deficits is still not well understood. There are conflicting results of studies comparing the long-term neurocognitive ability of professional football players who began playing tackle football before 12 years of age or prior to high school and those who began playing later. ${ }^{35,38}$ Additionally, several imaging and neurocognitive studies have evaluated the effect of repetitive subconcussive impacts

ABBREVIATIONS AYF = American Youth Football; HIE = head impact exposure; HIT = Head Impact Telemetry.

SUBMITTED November 8, 2016. ACCEPTED May 16, 2017.

INCLUDE WHEN CITING Published online September 12, 2017; DOI: 10.3171/2017.5.PEDS16627. 
over the course of a single season at youth, high school, and college levels and have demonstrated a relationship between measurable changes in white matter integrity and cognition with head impact exposure (HIE). ${ }^{2,3,13,22,25}$ However, the nature of the relationship of HIE to imaging and neurocognitive results is not fully understood, and conflicting results have been reported, although the conflicts may be due to methodological variations. Further research is needed to increase understanding of the effects of exposure to repetitive head impacts. In particular, HIE data, including magnitude, location, and frequency, need to be evaluated in the context of the associated activities contributing to the head impacts.

Head impact exposure has been studied at youth, high school, collegiate, and professional levels. Although the amount of available HIE data for youth-level football players has been limited, compared with data for high school and college players, there have been notable findings from past studies. ${ }^{9,17,28,31-33}$ Results from several studies showed that youth football players sustain head impacts approaching the magnitude of those sustained by high school and college football players. ${ }^{9,11,39}$ A study of HIE in youth football athletes aged 7-8 years showed that the majority of high-level impacts $(>80 \mathrm{~g})$ occur during practice rather than games. ${ }^{11}$ In a recent study, Campolettano et al. ${ }^{8}$ evaluated practice drills associated with high-magnitude $(>40 \mathrm{~g}$ ) head impacts and found that a greater proportion of impacts exceeding $40 \mathrm{~g}$ occurred in tackling drills compared with skill-type drills, even though approximately twice as much time was spent on skill-type drills.

In an effort to reduce the risk of concussion and overall HIE, some football organizations have taken steps to implement rule changes that affect practice structure. For example, in 2012 the Pop Warner youth football program limited the amount of contact allowed at each practice (one-third of total weekly practice time or 40 minutes total at each practice) and eliminated full-speed head-on blocking or tackling drills where athletes start more than 3 yards apart. ${ }^{29}$ Cobb et al. ${ }^{9}$ studied the effect of limiting contact in practices in youth football by comparing 1 team that adopted these practice limitations and 2 teams that did not. Players participating on the team with contact limitations in practice had 37\%-46\% fewer head impacts for the entire season than those on the 2 teams that did not implement contact limitations. ${ }^{9}$ Football organizations have also implemented educational programs such as the Heads Up Football program (http://usafootball.com/headsup) to train coaches on tackling technique, proper equipment fitting, and strategies to reduce playerto-player contact and concussions..$^{19,26} \mathrm{~A}$ study evaluating the effectiveness of the Heads Up Football program found that leagues implementing this program accumulated significantly fewer head impacts per practice than leagues that did not. ${ }^{19}$

These studies have shown that HIE can be influenced by the rules, regulations, and practice structure used by coaches, leagues, and organizations. However, there is only a limited understanding of how HIE varies among specific practice drills. The objective of this study was to evaluate the frequency, magnitude, and location of all head impacts in practice drills within a single youth foot- ball team through biomechanical data collection and detailed video analysis.

\section{Methods}

On-field head impact data from athletes participating in a local youth football team were collected during 1 season of play. The study protocol was approved by the Wake Forest School of Medicine institutional review board, and participant assent and parental written consent were properly acquired for participation in the study. The athletes enrolled in the study were participants in a youth football league affiliated with American Youth Football (AYF), in which athletes range in age from 6 to 14 years and are placed on teams based on age and weight guidelines of AYF. The athletes evaluated in this study participated in a team with athletes meeting the age and weight requirements of 10 years or younger with a maximum weight of $124 \mathrm{lbs}$ or 11 years old with a maximum weight of $104 \mathrm{lbs}$. For example, an 11-year-old weighing $100 \mathrm{lbs}$ would be placed on this team, but an 11-year-old weighing $110 \mathrm{lbs}$ would be placed on the next (higher) age- and weight-restricted team. Participation in the study was voluntary and the athletes had to properly fit into a Riddell Speed youth medium size or larger helmet to qualify for inclusion in the study. A certified athletic trainer was present at all practices and games to monitor athletes, regardless of participation in the study, for signs and symptoms of a concussion and assist in assessing any injuries. The athletic trainer documented all injuries that occurred in practices and games. If an athlete reported symptoms or showed signs of a concussion, the athletic trainer completed a Sport Concussion Assessment Tool (SCAT) evaluation, asked about the athlete's symptoms, and tested for cognition and balance. ${ }^{10}$ If a concussion was suspected, the athlete was referred to a sports medicine physician who would evaluate the athlete and confirm the diagnosis. ${ }^{23}$

Head impact data were collected by instrumenting the helmets of youth football players with the Head Impact Telemetry (HIT) System head acceleration measurement device (developed by Simbex) during all preseason, regular season, and playoff practices. Each study participant was issued and properly fitted with a Riddell Speed helmet with the HIT System installed. The HIT System measures location and magnitude of head impacts with an encoder, which is an array of 6 spring-mounted single-axis accelerometers oriented perpendicular to the surface of the head, a telemetry unit, a data storage device, and a battery pack. The encoder fits within the existing padding structure of a Riddell Speed helmet. The spring-mounted accelerometer design allows the encoder to remain in contact with the head throughout the duration of a head impact, ensuring measurement of head acceleration, not helmet acceleration. ${ }^{21}$ Data acquisition is triggered each time an instrumented helmet receives an impact greater than $10 \mathrm{~g}$, and a total of $40 \mathrm{msec}$ of data with $8 \mathrm{msec}$ of pre-trigger data are recorded at $1000 \mathrm{~Hz}$. The data from the encoder are transmitted via radio wave transmission to the sideline base unit. The data are then used to compute peak resultant linear accelerations, estimated peak resultant ro- 
TABLE 1. Descriptions of each drill classification

\begin{tabular}{|c|c|c|}
\hline Drill & Description & Purpose \\
\hline Dummy/sled tackling & Players tackle a dummy or sled & Reinforce wrapping while tackling \& improve form for blocking \\
\hline Install & Intra-team scrimmage & $\begin{array}{l}\text { Intra-team practice of offense \& defense game strategies in a game-like } \\
\text { situation }\end{array}$ \\
\hline Special teams & Players practice special teams plays & Practice alignment \& responsibilities for different special teams scenarios \\
\hline Multiplayer tackle & 1 defender vs 2 or 3 blockers & Improve blocking \& tackling form/technique \& improve footwork \\
\hline Oklahoma & $\begin{array}{l}2 \text { vs } 2 \text { or } 3 \text { vs } 3 \text { tackling drill w/ tackler, blockers, } \\
\quad \& \text { ball carrier }\end{array}$ & $\begin{array}{l}\text { Simulate game speed while working to improve blocking, running, \& } \\
\text { tackling technique in a confined space }\end{array}$ \\
\hline One-on-one & $\begin{array}{l}1 \text { vs } 1 \text { tackling drill w/ the } 2 \text { athletes starting less } \\
\text { than } 3 \text { yds apart* }\end{array}$ & Improve one-on-one tackling form \& technique \\
\hline Open-field tackling & $\begin{array}{l}1 \text { vs } 1 \text { tackling drill w/ the } 2 \text { athletes starting more } \\
\text { than } 3 \text { yds apart at an angle* }\end{array}$ & Improve form \& technique for tackling in full-speed game-like situations \\
\hline Passing & Athletes receive passes from coaches & Improve passing/catching skills \& hand-eye coordination \\
\hline Position skill work & Athletes separate into offense \& defense groups & Practice offensive- or defensive-specific skills \& game strategy \\
\hline Scrimmage & Inter-team scrimmage (i.e., w/ another team) & $\begin{array}{l}\text { Practice offense \& defense game strategy in a game-like situation btwn } \\
\text { adjacent age- \& weight-classified teams }\end{array}$ \\
\hline Tackling-drill stations & $\begin{array}{l}\text { Team is separated into smaller groups that com- } \\
\text { plete a series of tackling drills }\end{array}$ & $\begin{array}{l}\text { Practice tackling drills in smaller groups w/ a higher coach-to-player ratio } \\
\text { than in whole-team tackling drills }\end{array}$ \\
\hline
\end{tabular}

* The distance between athletes was determined by video review and from discussions with coaches about the specific drill setup. Study members were also present at practice and noted drill setup at the time of practice.

tational acceleration, location of impact, and other biomechanical indicators. The HIT System has been described in the literature and has been found to reliably compute peak linear acceleration, peak rotational acceleration, and impact location. ${ }^{4,5}$

Video was recorded for all practices, and postpractice video analysis was performed to ensure that head impacts occurred while the athletes were helmeted and to pair the video with the biomechanical data. For each drill, the name of the drill, start time, and end time were recorded such that each head impact was identified as belonging to a specific drill. Drill names and descriptions were provided by the coaches for the team at the beginning of the season and were classified as dummy/sled tackling, install, special teams, multiplayer tackle, Oklahoma, one-on-one, open-field tackling, passing, position skill work, scrimmage, and tackling drill stations (Table 1).

Head impact data collected over the season were used to quantify HIE for all practice drills in terms of rate, location of impact, and mean, median, and 95th percentile of head acceleration. The impact rate for each drill was quantified by dividing the number of impacts an athlete experienced for a drill in a practice by the time spent on that drill on that practice day. Generalized linear models were fitted, and Wald tests were used to assess differences among athletes and drills in the associated linear and rotational accelerations and the impact rate. For inference, log transformations were applied for all analyses due to the right-skewed distribution of the data. A Bonferroni correction was applied for all statistical tests to identify significant pairwise differences while maintaining the overall alpha level at 0.05 . All statistical analyses were performed using SAS software version 9.4 (SAS Institute Inc.). Mean values are reported with standard deviations and $95 \%$ confidence intervals where appropriate.

\section{Results}

A total of 2125 head impacts were recorded in 9 individual athletes during 30 contact practices. An additional 46 impacts were excluded from the analysis because they occurred during 6 noncontact practices (i.e., helmet only) throughout the season. The mean age and mass of the athletes on the team were $11.1 \pm 0.6$ years and $44.9 \pm 4.1$ $\mathrm{kg}$, respectively. The median and 95th percentile linear and rotational accelerations of all contact practice head impacts were $20.2 \mathrm{~g}$ and $56.4 \mathrm{~g}$ and 961.8 and $2337.3 \mathrm{rad} /$ $\mathrm{sec}^{2}$, respectively. The distribution of the number of head impacts experienced during all contact practices in a season for each athlete was right skewed and ranged from 83 to 459 head impacts, with a median value of 231 impacts. A summary of the total number of head impacts sustained by each athlete during all contact practices and their 95th percentile linear acceleration is shown in Fig. 1. All athletes were monitored by a certified athletic trainer for signs and symptoms of concussion, and no head impacts measured in this study resulted in a clinically diagnosed concussion. During practices, only 2 muscle strain injuries were observed among all of the athletes on this team.

The distribution of head impact magnitudes varied among the 11 practice drills, and impact magnitude was not proportional to the frequency or number of head impacts (Fig. 2). A summary of HIE data for each drill is shown in Table 2. Despite only accounting for $2 \%$ of all practice head impacts, open-field tackling accounted for $10 \%$ of practice head impacts $\geq 60 \mathrm{~g}$ and $17 \%$ of practice head impacts $\geq 80 \mathrm{~g}$. The install drill resulted in the highest number of impacts, $56 \%$ of practice impacts, but only $43 \%$ of impacts $\geq 60 \mathrm{~g}$ and $41 \%$ of impacts $\geq 80 \mathrm{~g}$. The drills with the lowest-magnitude head impacts were dummy/sled tackling, passing, and multiplayer tackle. 


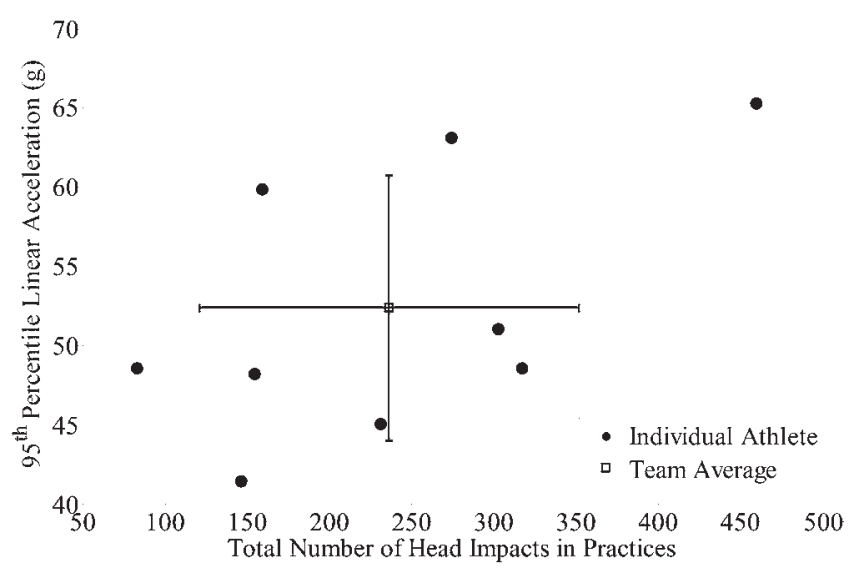

FIG. 1. Athlete and team average 95th percentile linear acceleration values versus total number of impacts for all contact practices. The team average is shown with standard deviation error bars.

Pairwise comparisons resulted in statistically significant differences in mean linear and rotational acceleration among drills (Fig. 3). Open-field tackling and oneon-one had significantly greater mean linear accelerations than many other drills practiced by this team. Oklahoma and tackling drill stations had significantly greater mean linear acceleration than passing. Additionally, open-field tackling had a significantly greater mean rotational acceleration than dummy/sled tackling, install, special teams, passing, and tackling drill stations.

Impact rate was described in terms of the mean number of impacts per minute per player, and pairwise comparisons were made among drills (Table 2). Multiplayer tackle had the highest impact rate, which was significantly greater than the impact rate for dummy/sled tackling, install, special teams, open-field tackling, passing, and position skill work. Oklahoma and one-on-one also had relatively high impact rates. The drills with the lowest impact rate were dummy/sled tackling and position skill work.
All impacts and impacts with peak linear acceleration $\geq 60 \mathrm{~g}$ were evaluated according to impact location (Fig. 4). The threshold of $60 \mathrm{~g}$ was chosen because it is a commonly used threshold in other similar studies of HIE. ., $^{7,34}$ Impacts to the front of the helmet were most common for all drills, except dummy/sled tackling. When only impacts $\geq 60 \mathrm{~g}$ were considered, impacts to the top of the helmet were most common in the Oklahoma, one-on-one, openfield tackling, and position skill work drills $(50 \%, 86 \%$, $44 \%$, and $50 \%$, respectively). Impacts to the front of the helmet were most common for impacts $\geq 60 \mathrm{~g}$ during install, multiplayer tackle, and tackling drill stations (45\%, $100 \%$, and $67 \%$, respectively). There were no impacts $\geq$ $60 \mathrm{~g}$ for dummy/sled tackling and passing.

\section{Discussion}

Head impact exposure in practice can be reduced by implementing rules, modifying practice structure, and educating coaches and leagues on methods to reduce concussion risk, but our understanding of HIE within specific practice drills and activities has so far been limited. $5,9,11,14,19,31,32,39$ The physiological thresholds for adverse effects from repetitive and/or concussive head impacts are not well understood; however, by quantifying HIE in football practice drills, this study is an important step in an evidence-based approach to modifying rules and practice structure to reduce HIE and head injury risk. In addition, because of the increasing numbers of concussions being evaluated by clinicians and the growing concern over the harmful effects of subconcussive impacts, clinicians must become better informed regarding the potential effects of sport-related activity (e.g., practice drills) on their patients' health. Results from this study demonstrate significant variability in HIE among youth football practice drills, with tackling drills generally having a distribution of higher-magnitude impacts and contact drills with multiplayer involvement resulting in higher impact frequency.

In this study, open-field tackling resulted in the highest

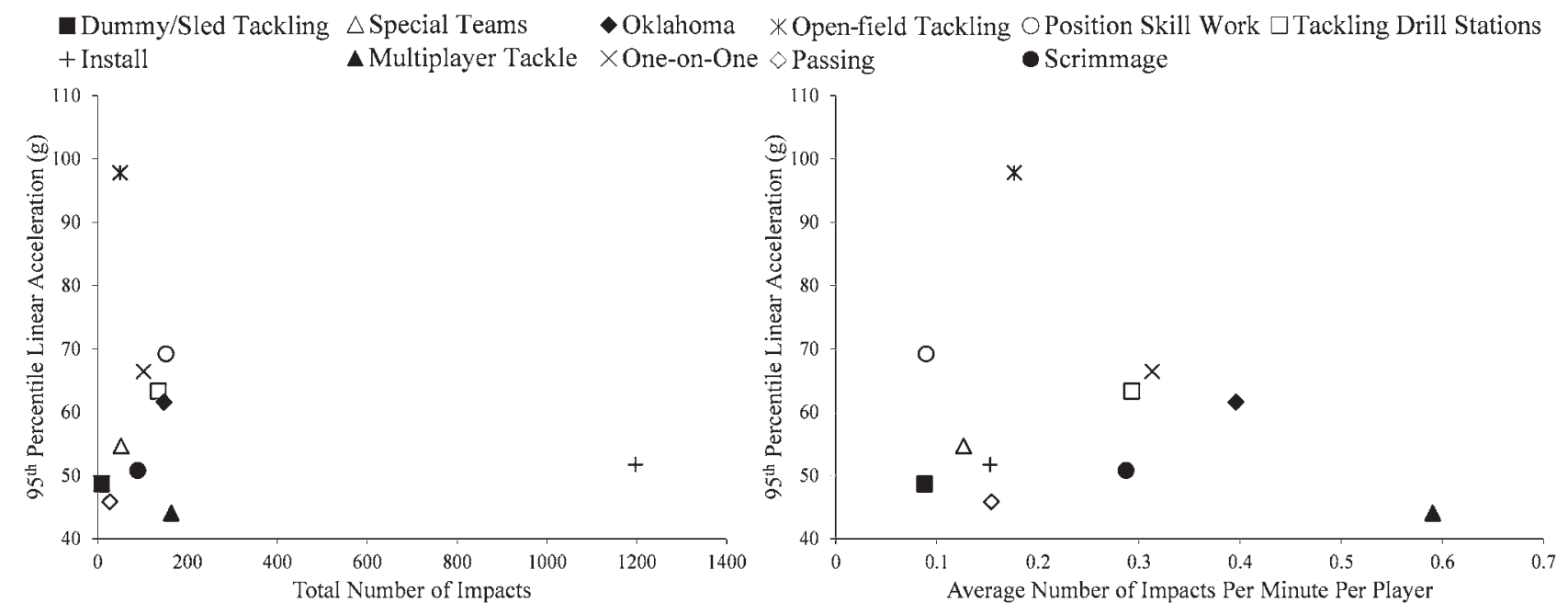

FIG. 2. The 95th percentile values for linear acceleration versus total number of head impacts in the season (left) and average number of impacts per minute per player (right) for each drill. 
TABLE 2. Summary of HIE data for each practice drill

\begin{tabular}{|c|c|c|c|c|c|c|c|}
\hline \multirow[b]{2}{*}{ Drill } & \multirow{2}{*}{$\begin{array}{c}\text { No. of } \\
\text { Impacts }\end{array}$} & \multicolumn{2}{|c|}{ No. of Impacts/Minute/Player } & \multicolumn{2}{|c|}{ Linear Acceleration $(g)$} & \multicolumn{2}{|c|}{ Rotational Acceleration $\left(\mathrm{rad} / \mathrm{sec}^{2}\right)$} \\
\hline & & Mean & $95 \% \mathrm{Cl}$ & 50th Percentile & 95th Percentile & 50th Percentile & 95th Percentile \\
\hline Dummy/sled tackling & 9 & $0.09^{a, b, c, d}$ & $0.05-0.17$ & 18.0 & 48.7 & 833.0 & 1576.3 \\
\hline Install & 1197 & $0.15^{\mathrm{e}, \mathrm{fg}, \mathrm{h}}$ & $0.14-0.17$ & 19.7 & 51.7 & 954.4 & 2280.0 \\
\hline Special teams & 52 & $0.13^{\mathrm{i}, \mathrm{j}, \mathrm{k}}$ & $0.09-0.17$ & 18.9 & 54.7 & 835.0 & 2152.8 \\
\hline Multiplayer tackle & 164 & $0.59 \mathrm{a}, \mathrm{e}, \mathrm{i}, \mathrm{l}, \mathrm{m}, \mathrm{n}$ & $0.41-0.85$ & 21.4 & 44.1 & 1018.4 & 2279.7 \\
\hline Oklahoma & 148 & $0.40^{\mathrm{b}, \mathrm{f}, \mathrm{j}, \mathrm{o}, \mathrm{p}}$ & $0.29-0.54$ & 22.9 & 61.6 & 1074.3 & 2958.0 \\
\hline One-on-one & 102 & $0.31^{c, g, k, q}$ & $0.24-0.42$ & 24.2 & 66.4 & 915.0 & 2584.2 \\
\hline Open-field tackling & 50 & 0.18 & $0.13-0.24$ & 24.7 & 97.8 & 1326.4 & 3816.3 \\
\hline Passing & 27 & $0.15^{\mathrm{m}, 0}$ & $0.11-0.21$ & 17.0 & 45.9 & 950.3 & 2415.5 \\
\hline Position skill work & 152 & $0.09^{h, n, p, q, r, s}$ & $0.07-0.11$ & 19.5 & 69.2 & 905.9 & 2556.6 \\
\hline Scrimmage & 89 & $0.29 r$ & $0.18-0.45$ & 18.9 & 50.8 & 869.8 & 2197.6 \\
\hline Tackling drill stations & 135 & $0.29^{\mathrm{d}, \mathrm{s}}$ & $0.19-0.45$ & 21.2 & 63.3 & 1010.2 & 2524.5 \\
\hline
\end{tabular}

a-s Drills that share the same superscript have mean numbers of impacts per minute per player that differ at $p<0.05$.

median and 95th-percentile linear and rotational accelerations (Table 2), with significantly greater mean linear and rotational acceleration compared with several of the other drills practiced by the team. This drill occurred in only 5 practices, and with a mean impact rate of 0.18 impacts per minute per player it resulted in a relatively small contribution to the total number of impacts in a single practice and the entire season. The high head acceleration values in this drill are most likely due to the athletes tackling at full speed and starting more than 3 yards apart from each other. Increased head impact severity with increased closing distance has been shown in a previous study; Ocwieja et al. found that head impacts with a longer closing distance ( $>10$ yards) between athletes resulted in significantly increased linear and rotational head accelerations than impacts with shorter closing distances. ${ }^{27}$ Although the distribution of impacts in the open-field tackling drill involved impacts of higher magnitude than those typically seen in games at the youth level of play, ${ }^{9}$ high-magnitude impacts resulting from full-speed tackling scenarios do occur in games and it may be beneficial to introduce proper and safe technique in these high-speed tackling scenarios in a practice environment. ${ }^{12,27}$ However, coaches and athletic trainers should be aware of possible high-magnitude impacts in this drill.

The one-on-one tackling drill was similar to openfield tackling as both were player-versus-player tackling drills, but the one-on-one drill had a closing distance of less than 3 yards and there was a greater focus on improving form and technique rather than simulating full-speed scenarios. Although this drill resulted in high-magnitude impacts, the shorter closing distance between athletes and the lower speed of tackling may have partially contributed to lower head impact magnitudes measured in one-on-one tackling than in open-field tackling. ${ }^{27}$ However, there was a higher impact rate in the one-on-one than in the openfield tackling drill, which was possibly due to the shorter closing distance, allowing for more iterations of the drill to be completed in a drill session.

The Pop Warner youth football program implement-
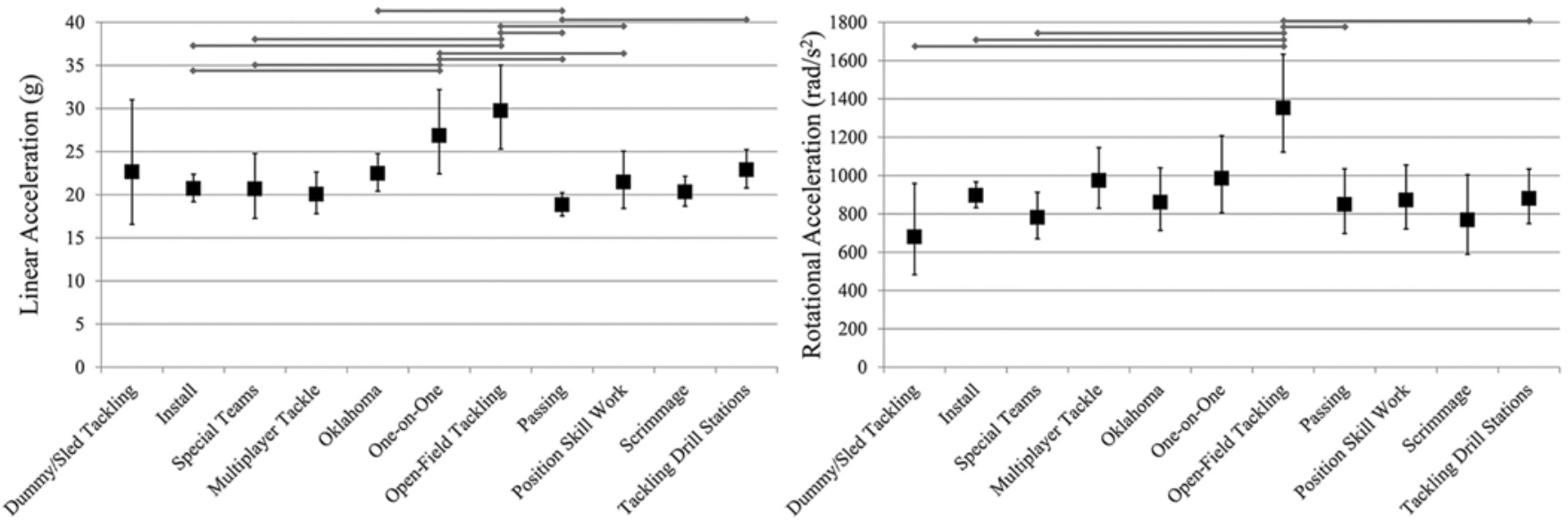

FIG. 3. Mean values and 95\% confidence intervals for linear (left) and rotational (right) acceleration for each drill. Lines connecting drills (at the top of the graphs) indicate significant differences $(p<0.05)$ in accelerations. The error bars indicate standard deviations. 
Dack $\square$ Front $\square$ Side $\square$ Top

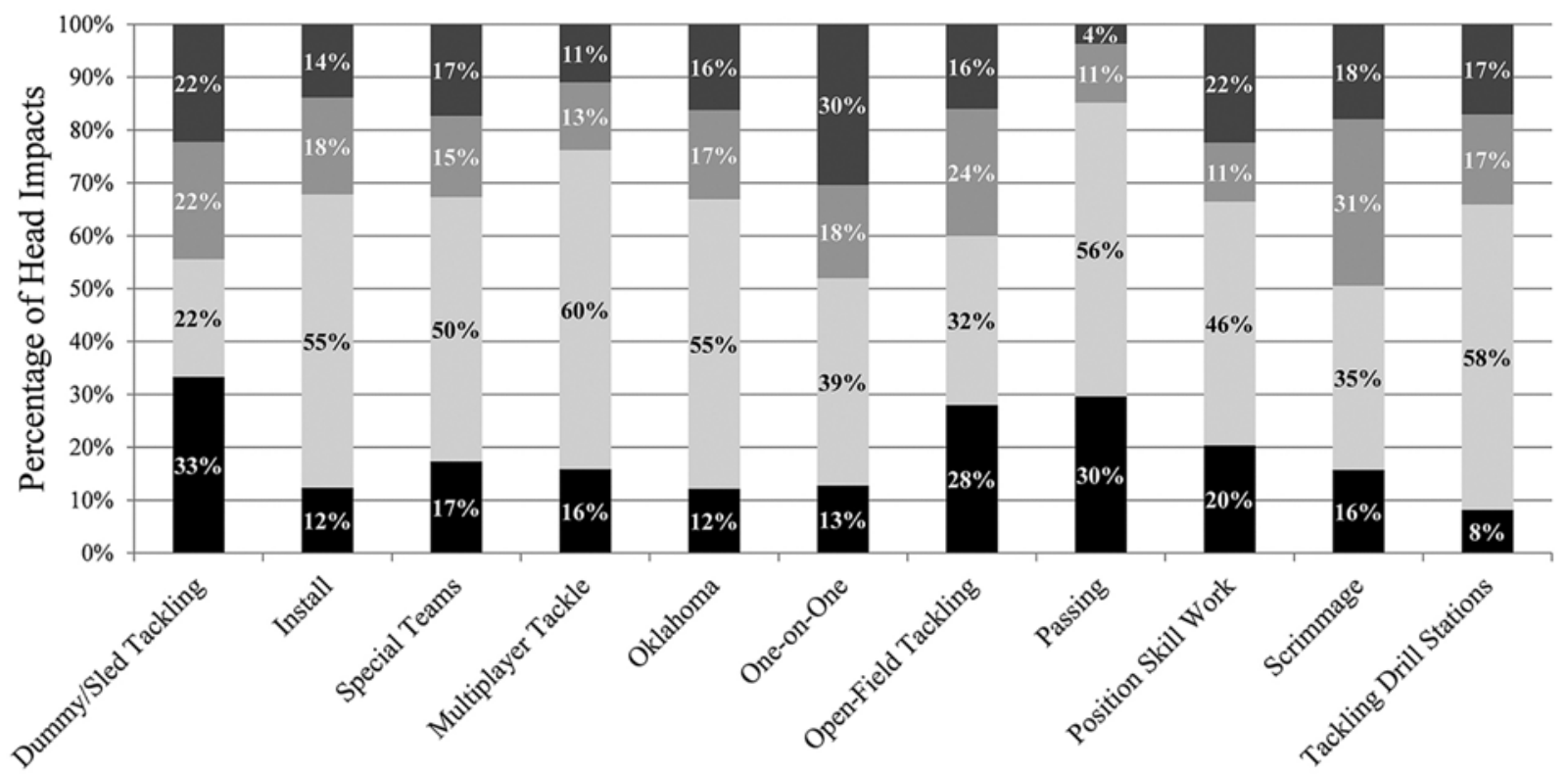

Back Front $\square$ Side $\square$ Top

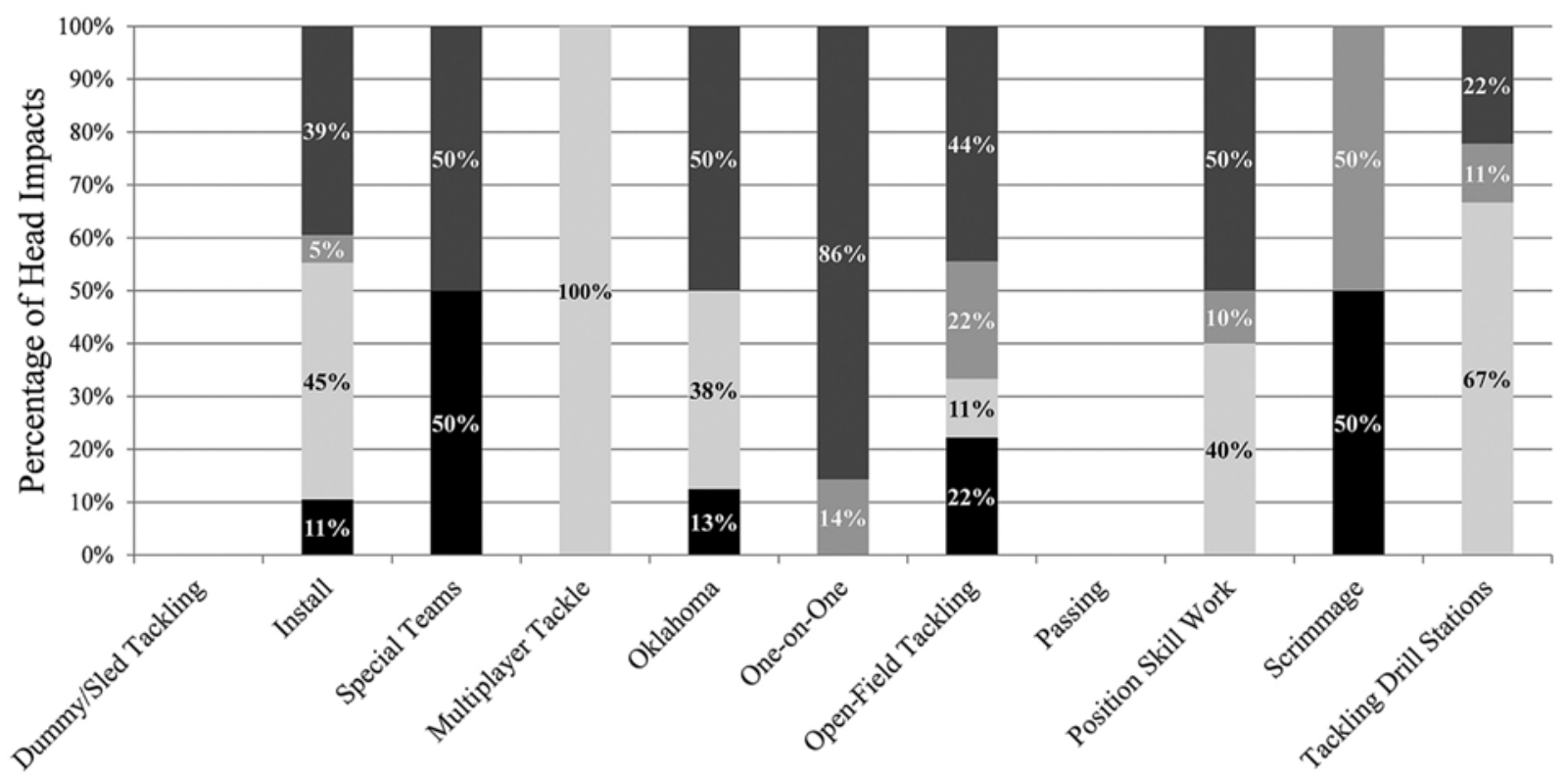

FIG. 4. Percentage of head impacts by impact location for each drill for all impacts (upper) and impacts $\geq 60 \mathrm{~g}$ (lower). Refer to Table 2 for the total number of impacts for each drill. No impacts $\geq 60 \mathrm{~g}$ were measured during dummy/sled tackling and passing drills. Due to rounding, not all columns total to $100 \%$.

ed rule changes in 2012 to eliminate full-speed head-on blocking or tackling drills with a closing distance between athletes greater than 3 yards and to reduce contact at practice to either 40 minutes total of each practice or one-third of the total weekly practice time. ${ }^{29}$ Kerr et al. compared injury rates among youth football players whose teams had implemented the educational program Heads Up Football and/or Pop Warner practice guidelines with players whose teams had not. ${ }^{18}$ The authors found that teams implementing Heads Up Football and/or Pop Warner rule changes had lower injury rates in practices than teams that did not implement either. ${ }^{18}$ However, the Pop Warner rule changes still permit full-speed drills where the athletes approach at an angle, but not straight ahead, which is comparable to the open-field tackling drill practiced by this team. The results presented in the current study, along with those from Kerr et al., support the importance of instilling proper technique in an effort to reduce head contact and indicate that considerations may be made to modify openfield tackling drills such that the athletes start at a shorter 
closing distance or remove this drill entirely from youth football practice structures. ${ }^{27}$

The Oklahoma drill resulted in the second highest number of impacts per athlete (Table 2). The high impact rate during Oklahoma is partially due to this drill involving 4-6 athletes in each play, rather than just 2 as seen in the player-versus-player drills, so each athlete participates in more iterations of this drill during a practice. Multiplayer tackle had the highest impact rate of all drills evaluated in this study but a distribution of relatively low-magnitude impacts, with the lowest 95th percentile linear acceleration of all drills $(44.1 \mathrm{~g})$. Although multiplayer tackle is a tackling drill, it is more focused on blocking and improving footwork than tackling the opposing player to the ground, unlike Oklahoma, in which the focus is more on replicating full-speed tackling scenarios and the movement of players is restricted within a chute. Additionally, the Oklahoma drill includes a ball carrier and ends when the ball carrier is tackled or successfully evades the tackler, whereas in multiplayer tackle there is no ball carrier and the drill ends when the defender is either stopped by the blockers or successfully evades the blockers (i.e., tackles a dummy or tags a coach who is in place of the quarterback). The shift in focus and drill setup for multiplayer tackle may explain why this drill resulted in lower-magnitude impacts but higher impact frequency than in other tackling drills.

Install was the most commonly practiced drill, resulting in the largest proportion of all practice impacts. However, the impact rate was significantly lower in this drill than in several of the tackling drills (Table 2). The lower impact rate may be due to the fact that coaches spend more time on instruction. In addition there was often a progression in the amount of contact in this drill, with the first few iterations typically being slower and involving only limited contact, and later progressing to more full-speed scenarios. Campolettano et al. ${ }^{8}$ found that the offense versus defense drill, similar to the install drill but with overall fewer players, had an impact rate similar to that of tackling drills in their study. However, Campolettano et al. also studied the offense or defense drill, which involved 11 offense or defense players with 3-4 proxy players on the other side and had a low impact rate due to the focus on positioning and execution of plays rather than on intrateam scrimmage. ${ }^{8}$ Although Campolettano et al. focused on impacts greater than $40 \mathrm{~g}$, a comparison with the install drill observed in the present study suggests that focusing initially on positioning and execution of plays, and gradually increasing the amount of contact can reduce impact frequency and impact magnitude. ${ }^{8}$ Scrimmage was similar to the install drill; however, the scrimmage drill was practiced between adjacent age- and weight-based teams. The team in our study only did the scrimmage drill with each adjacent (i.e., above and below) age and weight level once, each on separate practice days. The distributions of head acceleration values in this drill were comparable to those in the install drill, but the impact rate was higher for the scrimmage drill (Table 2). Nevertheless, more studies are needed to compare HIE data obtained during install drills and during scrimmage with adjacent age- and weight-classified teams in practice.

We also evaluated head impact data according to hel- met impact location. The most common impact location for all drills, except dummy/sled tackling, was the front of the helmet. A distribution with the highest number of impacts occurring at the front of the helmet is similar to findings in other studies of football athletes. ${ }^{9,11,39,41}$ However, when only impacts $\geq 60 \mathrm{~g}$ were evaluated, the top of the helmet was the most common impact location during open-field tackling, Oklahoma, one-on-one, and position skill work drills. This finding could be indicative of improper tackling technique, with athletes leading with their heads instead of leading with their shoulders while keeping their heads up. Studies of HIE of football athletes typically report the top of the helmet as having a distribution of the highest linear acceleration. ${ }^{9,11,41}$ More in-depth video analysis of tackling technique and head impact surface (e.g., helmet, player, or ground) is needed to better understand how tackling technique can be improved to lower HIE. The most common location for impacts $\geq 60 \mathrm{~g}$ during tackling drill stations was the front of the helmet, unlike other tackling drills. Due to the higher ratio of coaches to athletes in this drill, the coaches may have been able to better correct improper tackling technique, although further analysis of coach corrective behavior is needed to fully understand how coach interaction might influence HIE.

A few limitations of this study should be noted. First, only 9 athletes were sampled from 1 youth football team. This sample size is small compared with sample sizes in some other studies at the high school and collegiate level. ${ }^{20,39}$ The 9 youth athletes participating in this study demonstrated variations in overall $\mathrm{HIE}$, which could be due to differences in the athletes' involvement in practices and individual intensity. A sensitivity analysis removing individual athletes attenuated the strength of some relationships presented here; however, the general trends and overall conclusions of the study remained unchanged. The results of this study are also limited to a single youth football organization. The setup and technique that are being taught for each practice drill will be coach, league, and organization dependent; therefore, athletes on different teams may experience different HIEs while practicing similar drills. However, this study of HIE in youth football practice drills is ongoing, and future work will be conducted to evaluate HIE in specific practice drills for multiple seasons and across multiple age- and weight-based teams at the youth level. Several studies have shown that football players in older age groups (i.e., high school and college) experience higher-severity impacts more frequently, so further study of HIE in drills in older age groups would also increase our understanding of practice-related HIE and injury risk. ${ }^{7,17}$ The impact rate metric, impacts per minute per player, only takes into account measured impacts; it does not consider instances of no impact while participating in the drill. Lastly, the HIT System, which was used for biomechanical data collection, has some measurement error, but the error in 5 degrees of freedom (5DOF) acceleration measurements are within the range of acceptable error for other measurement devices and methods. ${ }^{4}$

\section{Conclusions}

In this study we quantified HIE in 11 youth football 
practice drills for a single age- and weight-restricted youth football team and demonstrated that HIE varies significantly between drills. Open-field tackling had a distribution of the highest head accelerations (compared with all other drills studied), and these data suggest that full-speed tackling drills with a closing distance of greater than 3 yards apart can result in high-magnitude impacts. The multiplayer tackle drill resulted in a distribution of relatively low head accelerations compared with other tackling drills, which may be due to a greater focus on blocking rather than tackling the opposing player(s) to the ground, but this drill resulted in the highest head impact rate. For all practice impacts, the highest percentage of impacts occurred at the front of the helmet, but for impacts $\geq 60 \mathrm{~g}$ the highest percentage of impacts occurred at the top of the helmet. These findings contribute to and improve our understanding of HIE in the youth football population. Along with future research, these data may be used to inform health professionals, so that they can better advocate for their patients' safety. These data can also inform coaches, leagues, and organizations about practice drills that may expose athletes to more frequent or higher-magnitude head impacts as well as methods to restructure practice drills and implement rules to reduce HIE.

\section{Acknowledgments}

Research reported in this publication was supported by the National Institute of Neurological Disorders and Stroke of the National Institutes of Health under Award No. R01NS094410. Dr. Jillian Urban was supported by the National Center for Advancing Translational Sciences, National Institutes of Health, through Grant No. KL2TR001421. The content is solely the responsibility of the authors and does not necessarily represent the official views of the National Institutes of Health. Special thanks to the Childress Institute for Pediatric Trauma at Wake Forest Baptist Medical Center for providing support for this study. We thank the youth football league's coordinators, coaches, parents, athletes, and athletic trainer, whose support made this study possible. We also thank Megan Anderson and Leslie Hoyt for their valuable assistance in data collection.

\section{References}

1. Aspen Institute: espnW/ASPEN Institute Project Play Survey of Parents on youth sports issues. Washington, DC: The Aspen Institute, 2014 (http://aspenprojectplay.org/ sites/default/files/espnw-Aspen $\% 20$ Institute\%20Project $\% 20$ Play\%20Survey\%20of\%20Parents\%20on\%20youth\%20 sports\%20issues.pdf) [Accessed June 22, 2017]

2. Bahrami N, Sharma D, Rosenthal S, Davenport EM, Urban JE, Wagner B, et al: Subconcussive head impact exposure and white matter tract changes over a single season of youth football. Radiology 281:919-926, 2016

3. Bazarian JJ, Zhu T, Zhong J, Janigro D, Rozen E, Roberts A, et al: Persistent, long-term cerebral white matter changes after sports-related repetitive head impacts. PLoS One 9:e94734, 2014

4. Beckwith JG, Greenwald RM, Chu JJ: Measuring head kinematics in football: correlation between the head impact telemetry system and Hybrid III headform. Ann Biomed Eng 40:237-248, 2012

5. Broglio SP, Eckner JT, Kutcher JS: Field-based measures of head impacts in high school football athletes. Curr Opin Pediatr 24:702-708, 2012
6. Broglio SP, Eckner JT, Paulson HL, Kutcher JS: Cognitive decline and aging: the role of concussive and subconcussive impacts. Exerc Sport Sci Rev 40:138-144, 2012

7. Broglio SP, Surma T, Ashton-Miller JA: High school and collegiate football athlete concussions: a biomechanical review. Ann Biomed Eng 40:37-46, 2012

8. Campolettano ET, Rowson S, Duma SM: Drill-specific head impact exposure in youth football practice. J Neurosurg Pediatr 18:536-541, 2016

9. Cobb BR, Urban JE, Davenport EM, Rowson S, Duma SM, Maldjian JA, et al: Head impact exposure in youth football: elementary school ages 9-12 years and the effect of practice structure. Ann Biomed Eng 41:2463-2473, 2013

10. Concussion in Sport Group: Sport Concussion Assessment Tool-3rd edition. Br J Sports Med 47:259, 2013 (http://bjsm. bmj.com/content/bjsports/47/5/259.full.pdf] [Accessed July 19, 2017]

11. Daniel RW, Rowson S, Duma SM: Head impact exposure in youth football. Ann Biomed Eng 40:976-981, 2012

12. Daniel RW, Rowson S, Duma SM: Head impact exposure in youth football: middle school ages 12-14 years. J Biomech Eng 136:094501, 2014

13. Davenport EM, Apkarian K, Whitlow CT, Urban JE, Jensen $\mathrm{JH}$, Szuch E, et al: Abnormalities in diffusional kurtosis metrics related to head impact exposure in a season of high school varsity football. J Neurotrauma 33:2133-2146, 2016

14. Duma SM, Manoogian SJ, Bussone WR, Brolinson PG, Goforth MW, Donnenwerth JJ, et al: Analysis of real-time head accelerations in collegiate football players. Clin J Sport Med 15:3-8, 2005

15. Gavett BE, Stern RA, McKee AC: Chronic traumatic encephalopathy: a potential late effect of sport-related concussive and subconcussive head trauma. Clin Sports Med 30:179, 2011

16. Guskiewicz KM, Weaver NL, Padua DA, Garrett WE Jr: Epidemiology of concussion in collegiate and high school football players. Am J Sports Med 28:643-650, 2000

17. Kelley ME, Urban JE, Miller LE, Jones DA, Espeland MA, Davenport EM, et al: Head impact exposure in youth football: comparing age- and weight-based levels of play. $\mathbf{J}$ Neurotrauma 34:1939-1947, 2017

18. Kerr ZY, Yeargin S, Valovich McLeod TC, Nittoli VC, Mensch J, Dodge T, et al: Comprehensive coach education and practice contact restriction guidelines result in lower injury rates in youth American football. Orthop J Sports Med 3:2325967115594578, 2015

19. Kerr ZY, Yeargin SW, Valovich McLeod TC, Mensch J, Hayden R, Dompier TP: Comprehensive coach education reduces head impact exposure in American youth football. Orthop J Sports Med 3:2325967115610545, 2015

20. Liao S, Lynall RC, Mihalik JP: The effect of head impact location on day of diagnosed concussion in college football. Med Sci Sports Exerc 48:1239-1243, 2016

21. Manoogian S, McNeely D, Duma S, Brolinson G, Greenwald $\mathrm{R}$ : Head acceleration is less than 10 percent of helmet acceleration in football impacts. Biomed Sci Instrum 42:383-388, 2006

22. McAllister TW, Ford JC, Flashman LA, Maerlender A, Greenwald RM, Beckwith JG, et al: Effect of head impacts on diffusivity measures in a cohort of collegiate contact sport athletes. Neurology 82:63-69, 2014

23. McCrory P, Meeuwisse WH, Aubry M, Cantu B, Dvorák J, Echemendia RJ, et al: Consensus statement on concussion in sport: the 4th International Conference on Concussion in Sport held in Zurich, November 2012. Br J Sports Med 47:250-258, 2013

24. McKee AC, Cantu RC, Nowinski CJ, Hedley-Whyte ET, Gavett BE, Budson AE, et al: Chronic traumatic encephalopathy in athletes: progressive tauopathy after 
repetitive head injury. J Neuropathol Exp Neurol 68:709735,2009

25. Munce TA, Dorman JC, Thompson PA, Valentine VD, Bergeron MF: Head impact exposure and neurologic function of youth football players. Med Sci Sports Exerc 47:15671576,2015

26. National Football League Foundation: Health \& safety. Heads Up Football. (http://www.nflfoundation.org/healthsafety) [Accessed June 22, 2017]

27. Ocwieja KE, Mihalik JP, Marshall SW, Schmidt JD, Trulock SC, Guskiewicz KM: The effect of play type and collision closing distance on head impact biomechanics. Ann Biomed Eng 40:90-96, 2012

28. Pellman EJ, Lovell MR, Viano DC, Casson IR: Concussion in professional football: recovery of NFL and high school athletes assessed by computerized neuropsychological testing-part 12. Neurosurgery 58:263-274, 2006

29. Pop Warner News Office: Rule changes regarding practice \& concussion prevention. PopWarner.com. June 3, 2012. (http://www.popwarner.com/Default.aspx?tabid=1403205\&m id=1475016\&newskeyid=HN1\&newsid=130019431\&ctl=news detail) [Accessed June 22, 2017]

30. Powell JW, Barber-Foss KD: Traumatic brain injury in high school athletes. JAMA 282:958-963, 1999

31. Reynolds BB, Patrie J, Henry EJ, Goodkin HP, Broshek DK, Wintermark M, et al: Practice type effects on head impact in collegiate football. J Neurosurg 124:501-510, 2016

32. Rowson S, Brolinson G, Goforth M, Dietter D, Duma S: Linear and angular head acceleration measurements in collegiate football. J Biomech Eng 131:061016, 2009

33. Rowson S, Goforth MW, Dietter D, Brolinson PG, Duma SM: Correlating cumulative sub-concussive head impacts in football with player performance-biomed 2009. Biomed Sci Instrum 45:113-118, 2009

34. Schnebel B, Gwin JT, Anderson S, Gatlin R: In vivo study of head impacts in football: a comparison of National Collegiate Athletic Association Division I versus high school impacts. Neurosurgery 60:490-496, 2007

35. Solomon GS, Kuhn AW, Zuckerman SL, Casson IR, Viano DC, Lovell MR, et al: Participation in pre-high school football and neurological, neuroradiological, and neuropsychological findings in later life: a study of 45 retired National Football League players. Am J Sports Med 44:1106-1115, 2016

36. Sporting Goods Manufacturers Association: 2012 Sports, Fitness and Leisure Activities Topline Participation Report. Silver Spring, MD: Sporting Goods Manufacturers Association, 2015 (https://s3.amazonaws.com/ustaassets/ assets/1/15/sgma_research_2012_participation_topline_ report.pdf) [Accessed June 22, 2017]

37. Sports and Fitness Industry Association: 2013 Sports,
Fitness and Leisure Activities Topline Participation Report. Silver Spring, MD: Sports and Fitness Industry Association, 2013 (http://www.espn.com/pdf/2013/1113/ espn_otl_sportsreport.pdf) [Accessed June 22, 2017]

38. Stamm JM, Bourlas AP, Baugh CM, Fritts NG, Daneshvar DH, Martin BM, et al: Age of first exposure to football and later-life cognitive impairment in former NFL players. Neurology 84:1114-1120, 2015

39. Urban JE, Davenport EM, Golman AJ, Maldjian JA, Whitlow CT, Powers AK, et al: Head impact exposure in youth football: high school ages 14 to 18 years and cumulative impact analysis. Ann Biomed Eng 41:2474-2487, 2013

40. Wilkins SA, Shannon CN, Brown ST, Vance EH, Ferguson D, Gran K, et al: Establishment of a multidisciplinary concussion program: impact of standardization on patient care and resource utilization. J Neurosurg Pediatr 13:8289,2014

41. Young TJ, Daniel RW, Rowson S, Duma SM: Head impact exposure in youth football: elementary school ages 7-8 years and the effect of returning players. Clin J Sport Med 24:416-421, 2014

\section{Disclosures}

The authors report no conflict of interest concerning the materials or methods used in this study or the findings specified in this paper.

\section{Author Contributions}

Conception and design: Urban, Kelley. Acquisition of data: Kelley, Kane, Miller. Analysis and interpretation of data: Urban, Kelley. Drafting the article: Urban, Kelley, Espeland. Critically revising the article: all authors. Reviewed submitted version of manuscript: all authors. Statistical analysis: Urban, Kelley, Espeland, Stitzel. Study supervision: Urban, Powers, Stitzel.

\section{Supplemental Information}

\section{Previous Presentations}

Portions of this work were presented in abstract form as proceedings at the 12th Annual Injury Biomechanics Symposium, Columbus, Ohio, June 6, 2016, and at the 2016 BMES Annual Meeting, Minneapolis, Minnesota, October 6, 2016.

\section{Correspondence}

Jillian E. Urban, Department of Biomedical Engineering, Wake Forest School of Medicine, 575 N Patterson Ave., Ste. 120, Winston-Salem, NC 27106. email: jurban@wakehealth.edu. 